\title{
Regression and dimensional analysis in coastal engineering: some pitfalls
}

\section{T. S. Hedges}

P. M. Jacovkis, Departamento de Computacion, Facultad de Ciencias Exactas y Naturales, Universidad de Buenos Aires

In this article a sentence in Appendix 1, regarding least absolute deviations (LAD or $\mathrm{L}^{1}$ norm) method, is misleading. The author says (page 224, second column)

'... two major difficulties have impeded its general adoption. Firstly, there are no closed-form formulae for evaluating $b_{0}$ or $b_{1} \ldots$ '

In fact, the optimal values $b_{0}$ and $b_{1}$ are the solutions of the following linear programming problem:

\begin{tabular}{|c|c|}
\hline $\mathrm{I}$ & $\min \sum_{i=1 \text { to } N} \mathrm{e}_{i}$ \\
\hline
\end{tabular}

subject to

\begin{tabular}{|l|l|}
\hline 2 & $e_{i}+b_{0}+b_{1} X_{i} \geq Y_{i}$ \\
\hline
\end{tabular}

\begin{tabular}{|l|l|}
\hline 3 & $\mathrm{e}_{i}-b_{0}-b_{1} X_{i} \geq Y_{i}$ \\
\hline
\end{tabular}

$i=1 \ldots, N, N$ number of observations,

that can be solved using the Simplex method. A detailed analysis may be seen, for instance, in the excellent book 'Linear programming' by V. Chvátal. $^{21}$

I think that Dr. Hedges is well aware of the solution because it is explained in some of the references of his paper, but a non- experienced reader may have the feeling that only approximate solutions exist.

Author's reply

Those readers familiar with Hudson's equation will have noticed a printing error in equation (5) of the paper. It should have $\operatorname{read}^{7}$

\begin{tabular}{|l|l|}
\hline 4 & Hudson: $N_{s}=\left(\mathrm{K}_{\mathrm{D}} \cot \alpha\right)^{1 / 3}$ \\
\hline
\end{tabular}

Those readers unfamiliar with Hudson's equation should now be able to make greater sense of the associated text.

Dr Jacovkis is thanked for emphasising the fact that, while use of the least-absolute-deviations (LAD) regression method may be a little more difficult than fitting using the least-squares (LS) procedure, there is no implication that the method is any more approximate. Chvátal's book ${ }^{21}$ could usefully have been added to the list of references in the paper.

\section{REFERENCES}

7. Hedges T. S. The core and underlayers of a rubble mound structure. Proceedings of the Institution of Civil Engineers, Conference on Breakwaters_Design and Construction, London, Thomas Telford Ltd, London, 1983, pp. 99-106.

21. ChVÁtal V. Linear Programming. W. H. Freeman, New York, 1983. 